\title{
Field measurements of coastal waves and currents in Portugal and Greece
}

\author{
Paillard Michel ${ }^{1}$, Prevosto Marc ${ }^{1,{ }^{*}}$, Barstow Stephen F ${ }^{2}$, Soares Carlos Guedes ${ }^{3}$ \\ ${ }^{1}$ IFREMER, Ctr Brest, F-92980 Plouzane, France. \\ 2 OCEANOR, Trondheim, Norway. \\ ${ }^{3}$ Inst Super Tecn, Lisbon, Portugal. \\ * Corresponding author : Marc Prevosto, email address : $\underline{\text { marc.prevosto@ifremer.fr }}$
}

\begin{abstract}
:
The MAST II WAVEMOD Project aimed at improving stochastic modelling of ocean waves and currents in coastal waters. In order to supplement existing data, two measurement campaigns were carried our, one on the Atlantic coast of Portugal, and, secondly, on the northern coast of Crete in the Mediterranean. The Portuguese measurements covered 7 months during winter 1993-1994, while off Crete, measurements started early in February 1994 and continued for 10 months, In both sites, two directional Waveriders and one non-directional Waverider were deployed along a transect our from the coast in water depths between 10 and $100 \mathrm{~m}$. In addition, the Mediterranean site also incorporated measurements of mean current velocities. Available satellite data were analysed to supplement the buoy data. In this paper, both measurement campaigns are described together with a presentation of some of the data collected. (C) 2000 Elsevier Science B.V. All rights reserved.
\end{abstract}

Keywords : waves, currents, Portugal, Greece 


\section{INTRODUCTION}

The field measurement of waves and currents along Portuguese and Greek coasts were an important task in the MAST II WAVEMOD Project which is described in [1] and in [2]. The objective of the project was to elaborate a probabilistic methodology for coastal site investigations. This type of methodology allows one to integrate in a mathematical model more complex or irregular phenomena through a combination of knowledge of physical phenomena and their actual observations. One of the aims of the project was to clarify how to adjust the probabilistic models to data from different sources, in order to decrease the duration of the necessary measurement campaigns and to increase the amount of available information at a site. 
Therefore short-term measurement programmes were conducted in order to supplement existing information and to provide data from simultaneous measurements that will be necessary to calibrate and validate the models. Use was made of hindcast predictions and of remote sensing data which will be pooled together in a data base.

In order to ensure that specific problems related with different local conditions would be identified and dealt with, two sites were chosen in the Atlantic coast of Portugal and in the Northern coast of Crete in the Mediterranean with different bottom slopes, fetch and climatological conditions. Both experiments are presented in this paper and some data examples are given.

\section{THE PORTUGUESE WAVE EXPERIMENT}

An area on the exposed west coast of Portugal, just north of the town of Figueira da Foz, was identified for the Atlantic field experiment. The area was chosen due to its simple topography, with a relatively wide continental shelf, gently sloping bottom and depth contours nearly parallel to the coast. The wave climate was also fairly well known through long term measurements being made by the Portuguese Hydrographic Institute, who also assisted with buoy deployment.

The wave climate in this area is swell dominated as a result of the frequent storms further to the north. Winds are locally predominantly northerly to north westerly. Wave directions are as a result predominantly north westerly although southwesterly storms do occur occasionally.

The Norwegian company OCEANOR deployed 3 wave buoys along a line perpendicular to the coast (Fig. 1) on 19th October 1993. Directional Waveriders were placed in $20 \mathrm{~m}$ and $72 \mathrm{~m}$ water depth and a non-directional Waverider was located at $50 \mathrm{~m}$. The Directional Waverider is described elsewhere in these proceedings [4]. The Waverider was moved to $12.5 \mathrm{~m}$ depth on 4th March 1994. The directional buoy operated by the Portuguese Hydrographic Institute was located close to the $100 \mathrm{~m}$ contour a little to the south of the buoy array and provided data for the latter part of the experiment. The field measurements continued until 25th May when all equipment was retrieved.

All the buoys operated by OCEANOR transmitted (directional) spectra by way of the ARGOS satellite system whilst raw data were stored internally on the buoys. In total, 180 days of directional spectra are now available from the $70 \mathrm{~m}$ location, 150 days from $20 \mathrm{~m}$, and 90 and 80 days respectively from the Waverider at $50 \mathrm{~m}$ and $12.5 \mathrm{~m}$ depth. A composite time series of significant wave height, peak wave period and wave direction at the spectral peak is shown in Fig. 2 for the duration of the experiment.

The most remarkable feature of the wave climate during the experiment was the high level of long periodic swell. At least 15 independent events can be identified in the peak period time series when it exceeds 18 secs. and on 4 occasions over 20 secs. This was a result of a steady stream of energetic storms 
in mid-Atlantic during the winter. The source of these waves is clearly identified in the wave direction time series, the most energetic waves almost invariably arriving at the experiment area from north to westerly directions.

The 3 major storms on 6th and 10th January and 4th February all produced peak significant wave heights around $8 \mathrm{~m}$. In all 3 cases the high waves were a result of a combination of high swell and wind sea associated with slow moving depressions centred close to the British Isles.

An increasingly important contribution to wave climate studies is from remote sensing satellites equipped with wave height measuring altimeters (currently Topex/Poseïdon and ERS-1) and synthetic aperture radar or SAR (ERS-1). Available satellite data are being analysed to supplement the buoy data.

The Directional Waverider at $72 \mathrm{~m}$ was located near to a Topex/Poseïdon ground track (Fig. 1). The altimeters on board provide measurements of both significant wave height and wind speed along the track. The Portuguese Hydrographic Institute's buoy was, similarly, located close to the ERS-1 ground track.

Topex/Poseïdon flew over the area soon after the 6th January storm. In Fig. 3 is shown the variation of wave height and wind speed with latitude along the ground track, which is shown in Fig. 1. The satellite measures significant wave height almost identical to the buoy at its closest approach. Wave height decreases slowly towards the north as the satellite passes over shallower water. The last measurement before the satellite passes over the coast is somewhat higher again. In this location, water depth is $10-20$ $\mathrm{m}$ and wave breaking is probably occurring.

A scene from the ERS-1 SAR is shown in Fig. 4 from an area slightly north of the field experiment and clearly shows wave refraction as the waves approach the coast. In Fig. 5 are shown inverted SAR spectra from an offshore and inshore part of the scene. Both lower wave height, change in the wave direction, and narrower directional spread are apparent in the inverted wave from the inner location.

Further, on 29th March a scene is available covering the field experiment area (Fig. 6). Cabo Mondego, just north of Figueira da Foz (Fig. 1), can clearly be seen and a beautiful swell refraction pattern is visible to the south of the cape.

\section{THE GREEK WAVE EXPERIMENT}

The Mediterranean site was chosen, together with our Greek partner in the project, the company MARTEDEC, on the north-western coast of the island of Crete after considering potential sites in the Hellenic seas. A small bay, exposed to the north and situated on the western side of the town of RETHYMNON was identified for the Mediterranean field experiment. 
The choice was due to several factors: relatively long fetch in the Aegean sea, topography, sea conditions, wind conditions, logistic facilities, etc. The topography of the site chosen is not very complex and the slope is around 2.5\%. As a result, diffraction and reflection are not too important (see Fig. 7).

The site is essentially exposed to waves generated by the different local wind regimes with westerlies dominating. Northerlies are more common in summer. North easterlies also occur as a result of low pressure in the eastern Mediterranean. Although summer and winter climatology are quite different, severe sea conditions (Hs>4m) near shore may occur at any season. Wave directions at the site are predominantly north west to north east.

Tides are not significant in this area and local currents are essentially wind generated. The general circulation of the water in this area is slow (a few centimetres per second).

The French company METEOMER, associated with IFREMER, deployed three wave buoys along a line approximately perpendicular to the coast. Two DATAWELL Directional WAVERIDER were located at 10 and $100 \mathrm{~m}$ metres depth and one non directional DATAWELL WAVERIDER buoy was located at $20 \mathrm{~m}$ depth. The campaign started on the 1st February 94 and continued until the end of November. Both winter and summer sea conditions therefore were covered. Three current-meters (2 AANDERAA RCM7 and 1 INTEROCEAN S4) were also deployed near to each buoy at $8.5 \mathrm{~m}$ below sea surface in order to measure the mean current velocity. The S4DW was installed, in parallel to the project, for intercomparison studies.

The buoy operated by METEOMER transmitted raw data by means of VHF to a land station situated on a building of the Municipality of RETHYMNON just above the site (Altitude 40m). All raw data were stored from the 3 buoys for detailed wave studies. A technician from the METEOMER company was permanently stationed on the site during the campaign. In this way, a high data recovery level was obtained. The continuity of data from the three buoys has been very good from February to November (Fig. 8 shows $\mathrm{H}_{\mathrm{s}}$ and $\mathrm{T}_{\mathrm{z}}$ from the $100 \mathrm{~m}$ water depth buoy. The figures are the same for the other buoys).

During the first four and the two last months of the campaign, the site was exposed to many short storms which generated very high sea states, as we can see on the time series plots of $H_{s}$ (Fig. 8 and 9), with $\mathrm{H}_{\mathrm{s}}$ exceeding 3 metres (and maximum $\mathrm{H}_{\mathrm{s}}>5 \mathrm{~m}$ ). One has to be aware that the Waverider at $10 \mathrm{~m}$ depth was exposed at times to breaking wave forces, in these situations the response of the buoy-mooring system and the wave sensor may therefore affect the measurements.

During the various storms, it could be observed from the land station that the limit of the breaking zone was determined by the 10 metre depth contour. The buoy was submitted to very strong forces and its behaviour which may overestimate $\mathrm{H}_{\mathrm{S}}$ has to be studied carefully. Figure 10 shows the time history of $\mathrm{H}_{\mathrm{S}}$ during one of these storm, and figure 11 shows a close-up of the previous figure at the end of the 
storm. Note that erroneous values of $\mathrm{H}_{\mathrm{S}}$ due to buoy behaviour have been suppressed from these plots. We observe that $\mathrm{H}_{\mathrm{s}}$ at the 10 and $20 \mathrm{~m}$ depths are quite similar and significantly higher in deep water giving a coherent picture. Figure 12 shows the mean period $\mathrm{T}_{\mathrm{z}}$ for the same time period as figure 11 . The difference between deep water depth and near coast is also observed although less important.

Finally, plots are given of $\mathrm{H}_{\mathrm{S}}$ versus $\mathrm{T}_{\mathrm{z}}$ (Fig. 13) from the complete data base. An interesting parameter for each sea state is the significant steepness, defined as the steepness of a wave in deep water of $\mathrm{H}_{\mathrm{S}}$ metres height with a period of $\mathrm{T}_{\mathrm{z}}$ seconds: $\mathrm{s}=2 \pi \mathrm{H}_{\mathrm{s}} / \mathrm{T}_{\mathrm{z}}^{2}$.

Note that in the case of a Pierson-Moskowitz spectrum, this parameter is constant and equal to 1/19.7. We observe that in deep water, (Fig. 13, left) the plot is bounded on the upper side by a constant maximum value of $s$, around $1 / 17$. This is lower than $1 / 13$ which is generally found for exposed sites. For the high energy level $\left(\mathrm{H}_{\mathrm{s}}>1.5 \mathrm{~m}\right), \mathrm{s}=1 / 19.7$, relating to a fully-arisen sea and Pierson-Moskowitz spectrum, seems to be a central value in the case of our data. In shallow water (Fig. 13, right) the limit significant steepness is the same, and so shows to be related to the period (s defined previously) and not to the wavelength ( $\mathrm{s}_{10}$ defined by $\mathrm{s}=\mathrm{H}_{\mathrm{s}} / \lambda_{\mathrm{z}}, 2 \pi / \mathrm{T}_{\mathrm{z}}^{2}=\frac{\mathrm{g}}{\lambda_{\mathrm{z}}} \tanh \mathrm{d} \frac{2 \pi}{\lambda_{\mathrm{z}}}$, with $\mathrm{d}$ the water depth).

These data have been extensively used during the WAVEMOD project for more precise studies, particularly concerning the nonlinear characteristics of the waves.

\section{CONCLUSIONS}

Two sites have been presented, one on the Portuguese coast and, secondly on the Cretan coast in Greece. The Portuguese field measurements covered 7 months; the wave climate during the experiment being dominated by a high level of long periodic swell. Three major storms also produced peak significant wave heights around $8 \mathrm{~m}$. The Greek field measurements run from February until November 94 and during the first four months (essentially March) and the last two months different storms produced peak significant wave heights up to around $5 \mathrm{~m}$.

Both experiments have produced very interesting measurements of typical and extreme sea states which constituted a valuable data base for the MAST II WAVEMOD Project.

\section{ACKNOWLEDGEMENTS}

This work was partly funded by the Commission of the European Communities, Directorate General for Science, Research and Development under contract $n^{0}$ MAS2-CT920025. The participants in the WAVEMOD project were IST from Portugal, the Laboratoire d'Hydraulique de France, STNMTE, STCPMVN and IFREMER from France, MARTEDEC and the National Technical University of Athens from Greece, SINTEF and OCEANOR ASA from Norway, Delft University of Technology from Netherlands and Programa de Clima Maritimo from Spain. Special mention is made to the Portuguese 
Hydrographic Institute, which is also participating in the project and which provided the field support for the Portuguese experiment, to the Institute of Marine Biology in Crete which provided the field support for the Greek experiment and to MARTEDEC which was involved in the Greek field campaign.

\section{REFERENCES}

[1] C. Guedes Soares, 1993, «Probabilistic Methodology for Coastal Site Investigation Based on Stochastic Modelling of Waves and Currents» Presented at MAST Days, Brussels, 15, 16, March 1993.

[2] M. Prevosto, M. Paillard, «Projet MAST II WAVEMOD: Probabilistic Methodology for Coastal Site Investigation based on Stochastic Modelling of Waves and Currents», 3èmes Journées Nationales Génie civil - Génie côtier, Sète, France, March 1994.

[3] C. Guedes Soares, H.E. Krogstad, M. Prevosto, 1994, «WAVEMOD Project : Probabilistic Models for Coastal Site Investigations.» Proc. OCEANS 94 Conference, Brest, France, Sept. 1994.

[4] S.F. Barstow and T. van der Vlugt, 1994, «A Field Validation of the Directional Waverider in a SEAWATCH Buoy» Proc. OCEANS ‘94 Conference, Brest, France, Sept. 1994. 
1. Map of the Portuguese Field Experiment area. Location of Directional Waveriders are indicated by DW, WR for the Waverider, and PHI for the Portuguese Hydrographic Institute's directional buoy. The Topex/Poseïdon ground track referred to in the text is indicated by the dashed line.

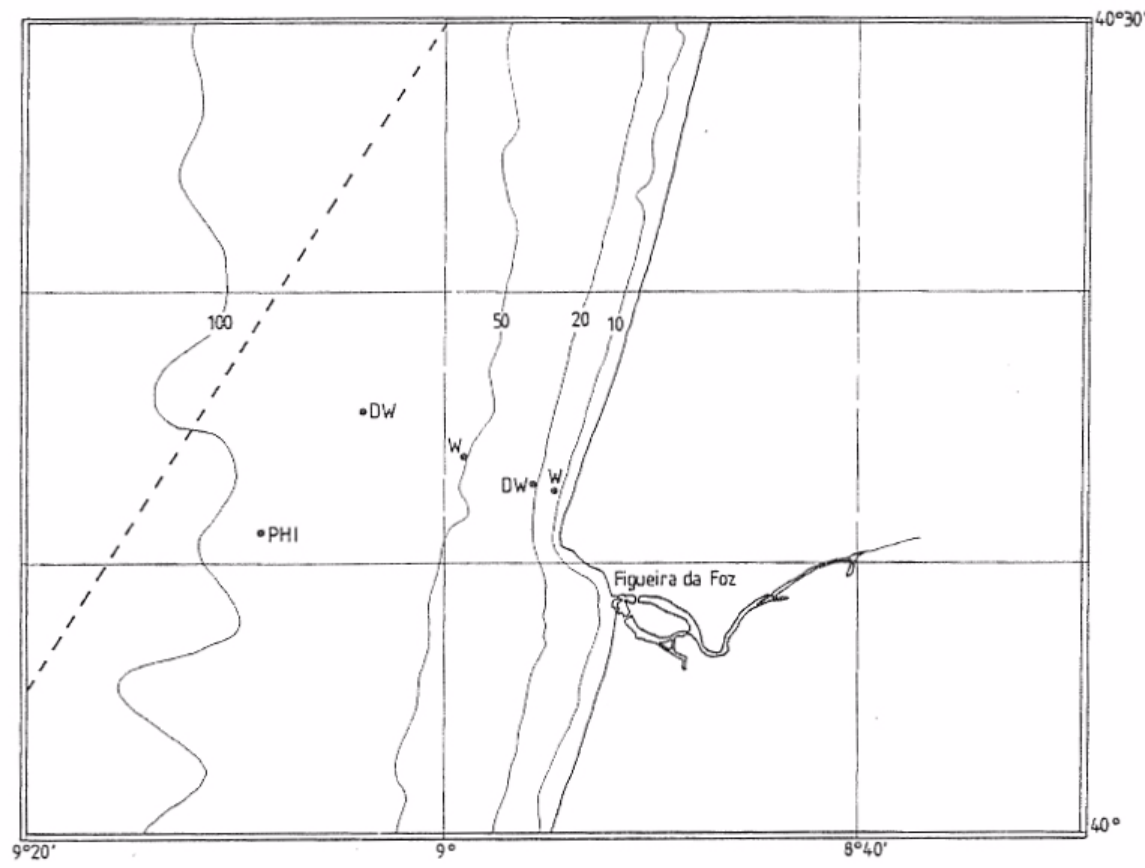


2. Composite time series plot showing a) significant wave height, b) peak wave period, and c) mean wave direction at the peak wave period from the directional Waveriders for the duration of the field experiment.

a)

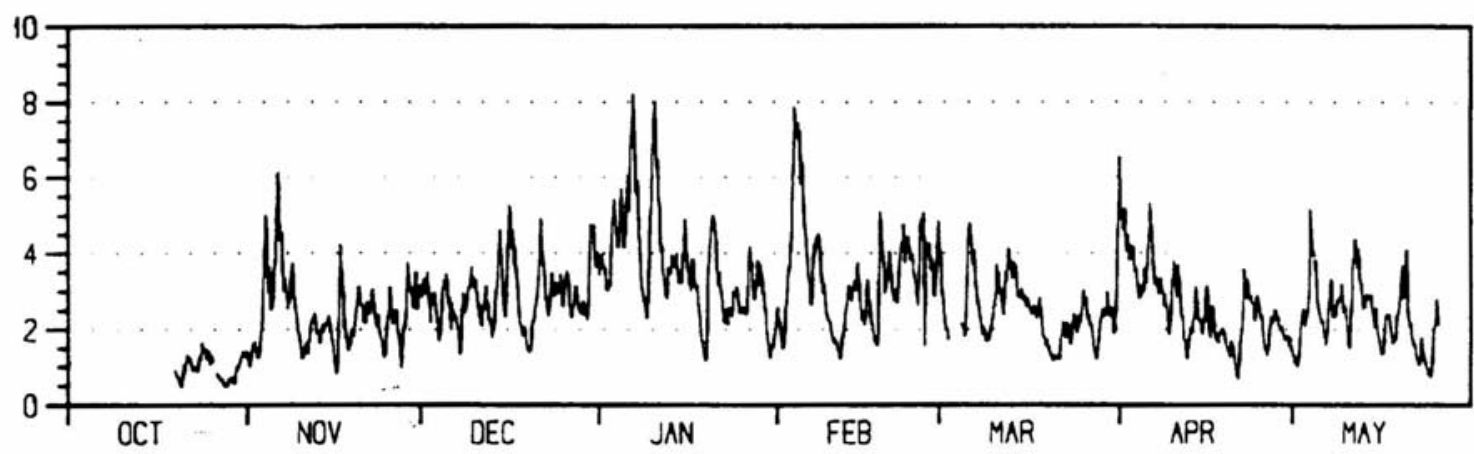

b) 25

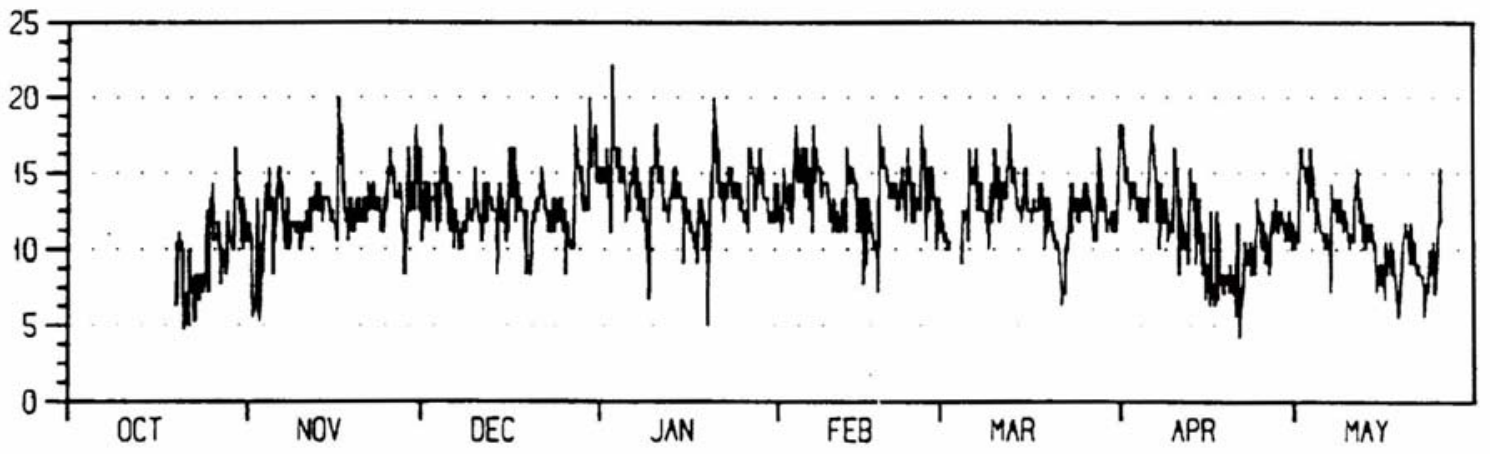

c) 405

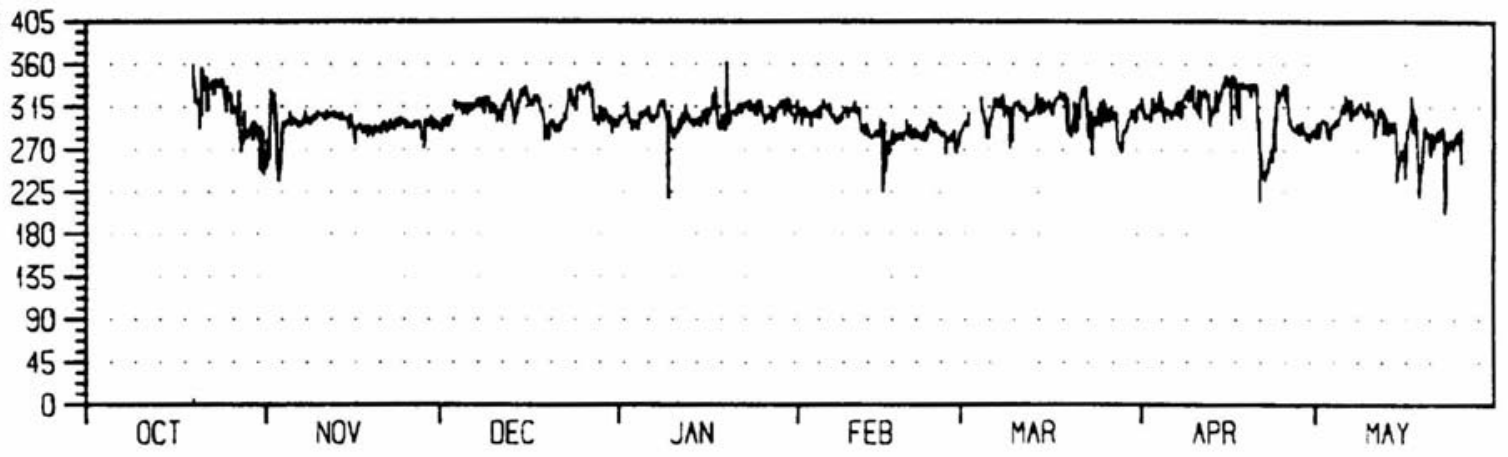


3. Variation of significant wave height (solid line) and wind speed (dashed line) along the Topex/Poseïdon ground track in Fig. 1 for 7th January at 12.30 UTC

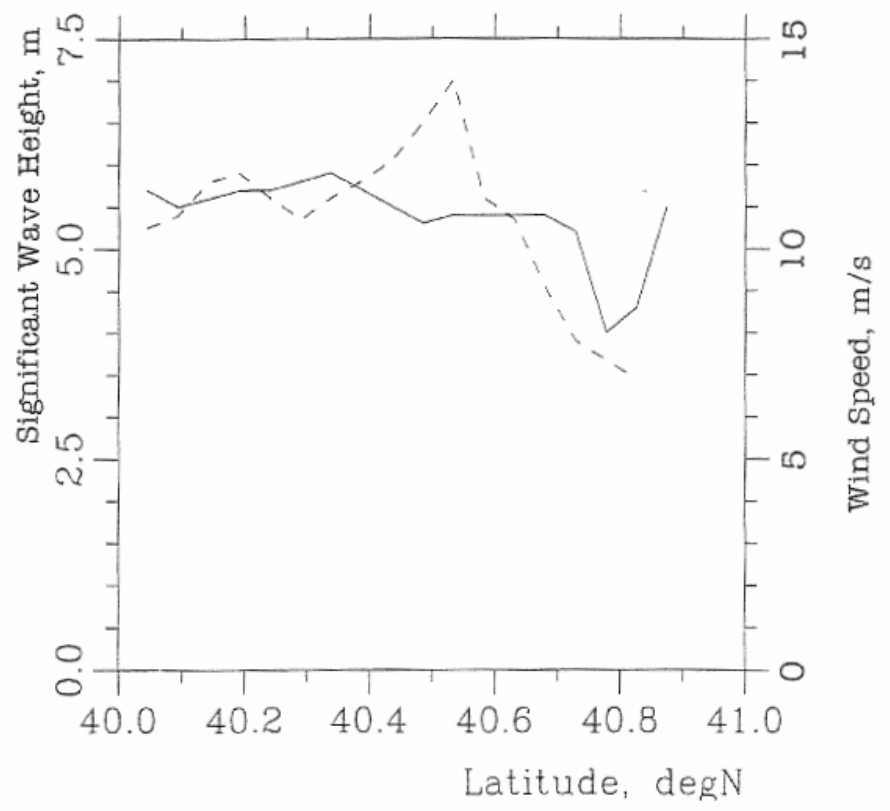


4. Detail of a ERS-1 SAR scene from 4th December 1993 at 2130 just north of the field experiment area. Wave refraction is evident as waves approach the coast which is visible at the right hand edge of the scene. A ship is also seen at the top left hand corner.

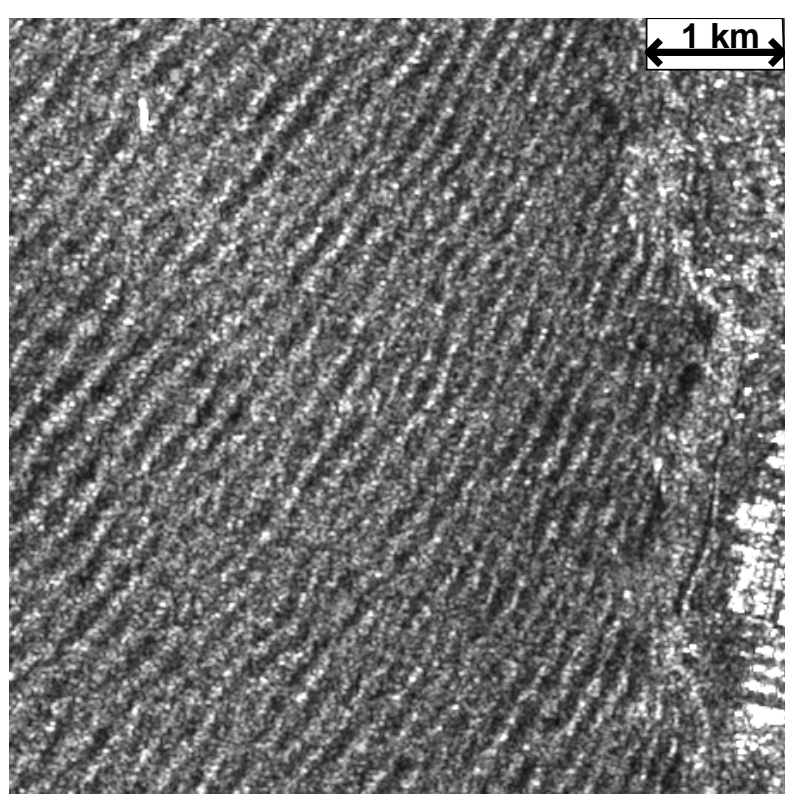


5. Inverted directional wave spectra from two sub-regions of the SAR scene in Fig. 4. The upper one is taken about $50 \mathrm{~km}$ offshore whilst the lower is close to the coast. North is approximately along the $\mathrm{x}$-axis
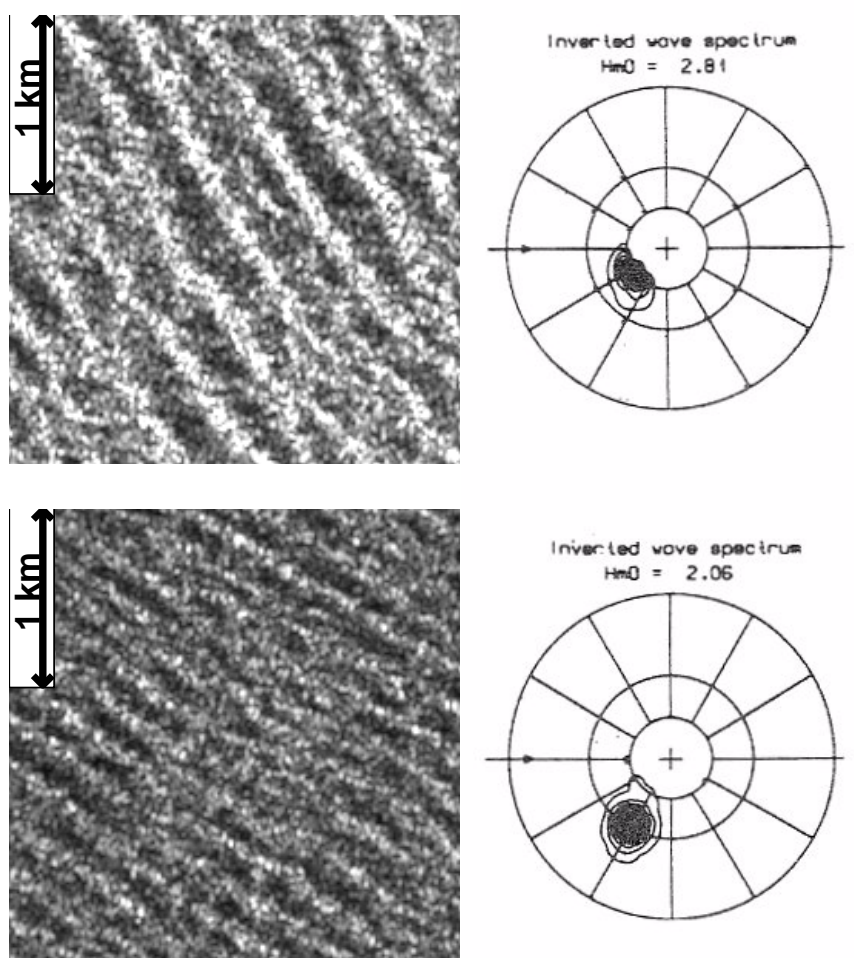
6. ERS-1 SAR scene taken over the field experiment area on 29th March.

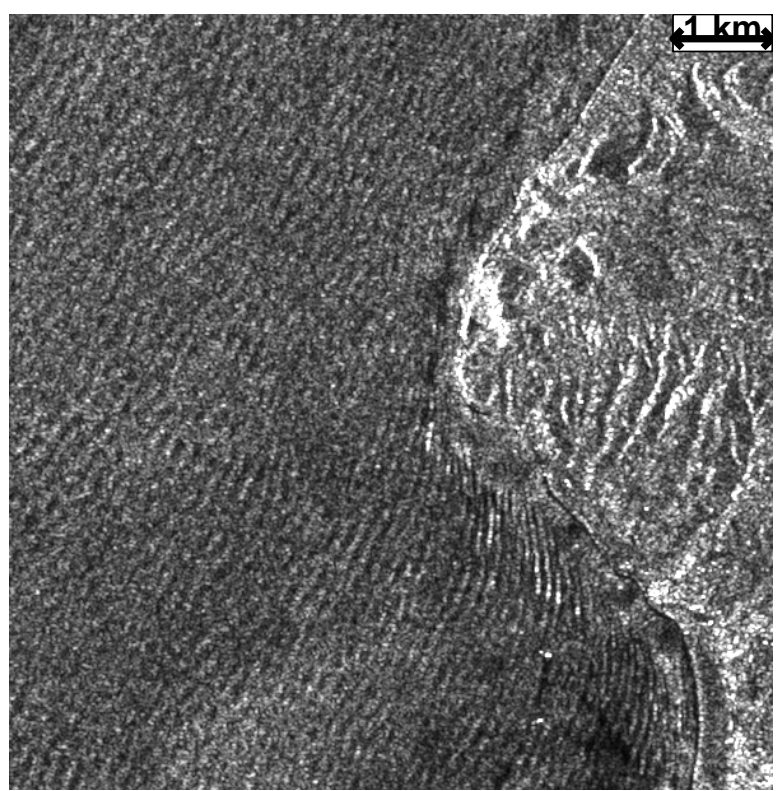

7. Map of the Greek experiment area and location of instruments

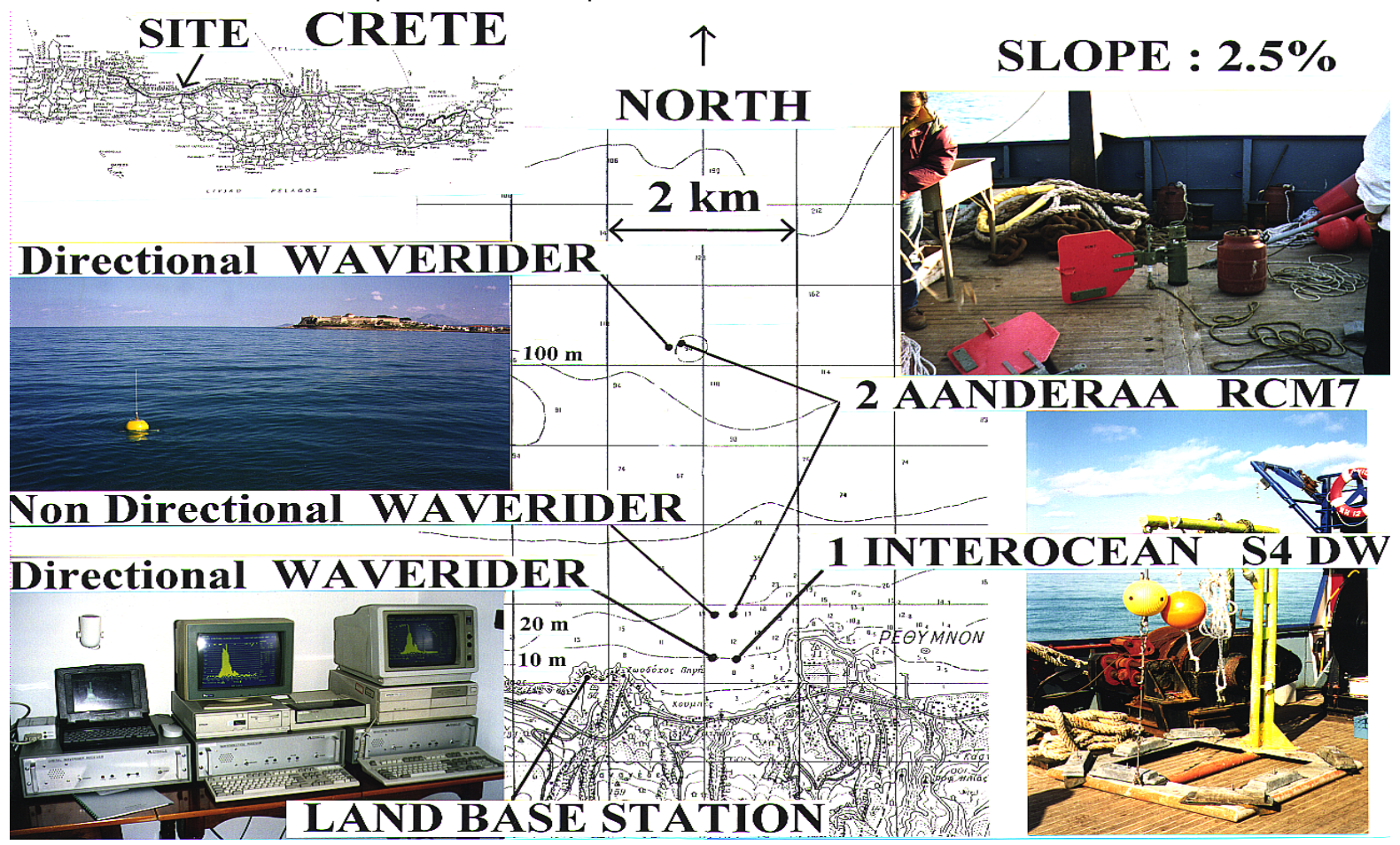


8. $\mathrm{H}_{\mathrm{s}}$ and $\mathrm{T}_{\mathrm{z}}$ during all the campaign (buoy $100 \mathrm{~m}$ )
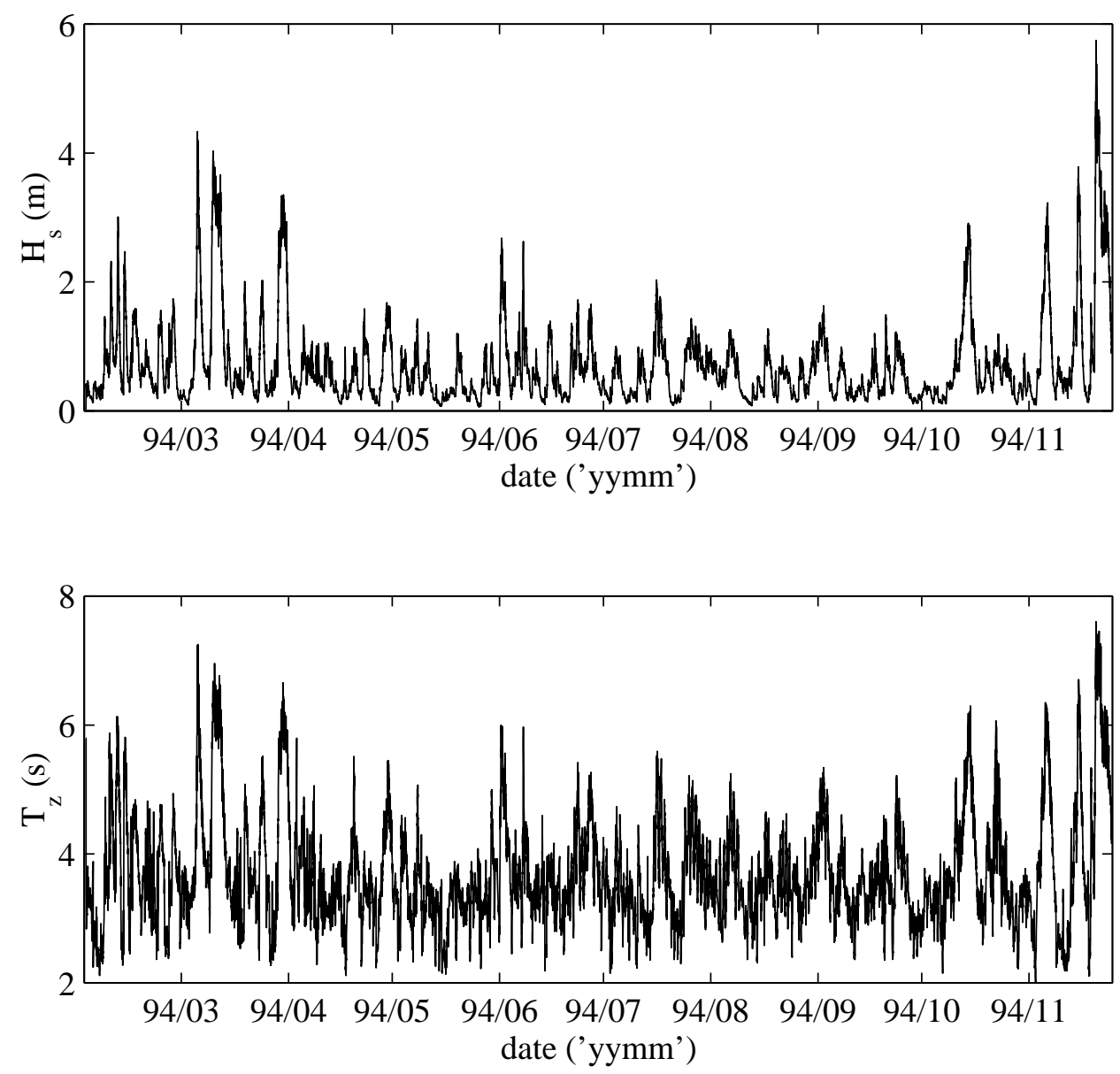

9. Time series plots of $\mathrm{H}_{\mathrm{S}}$ from the 3 DATAWELL.

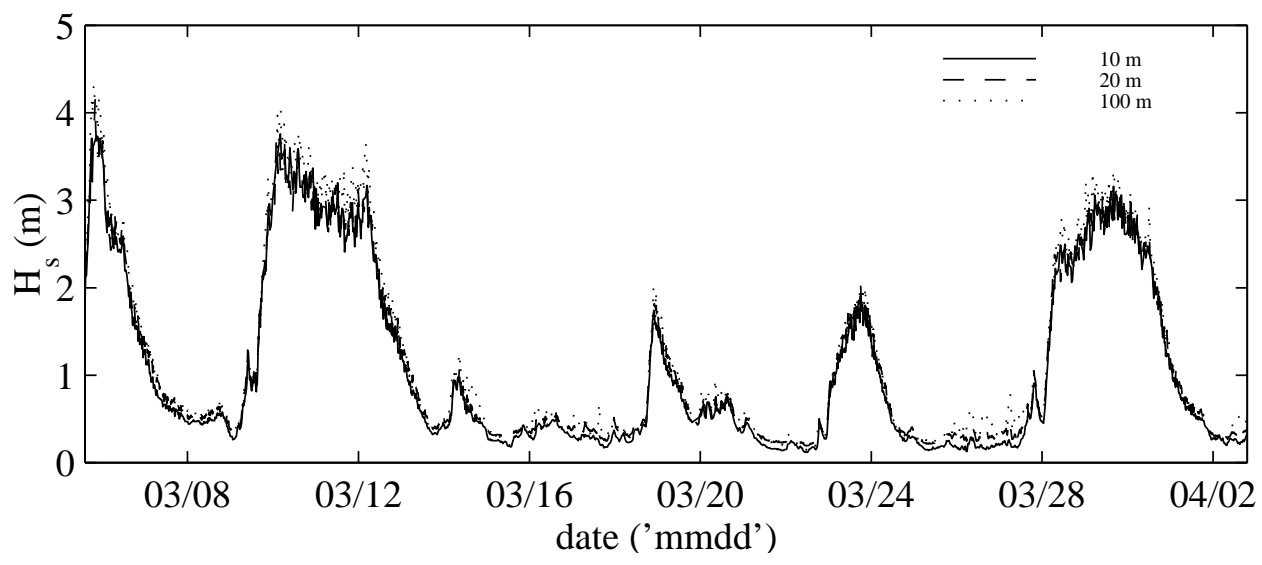


10. Storm on 10th March.

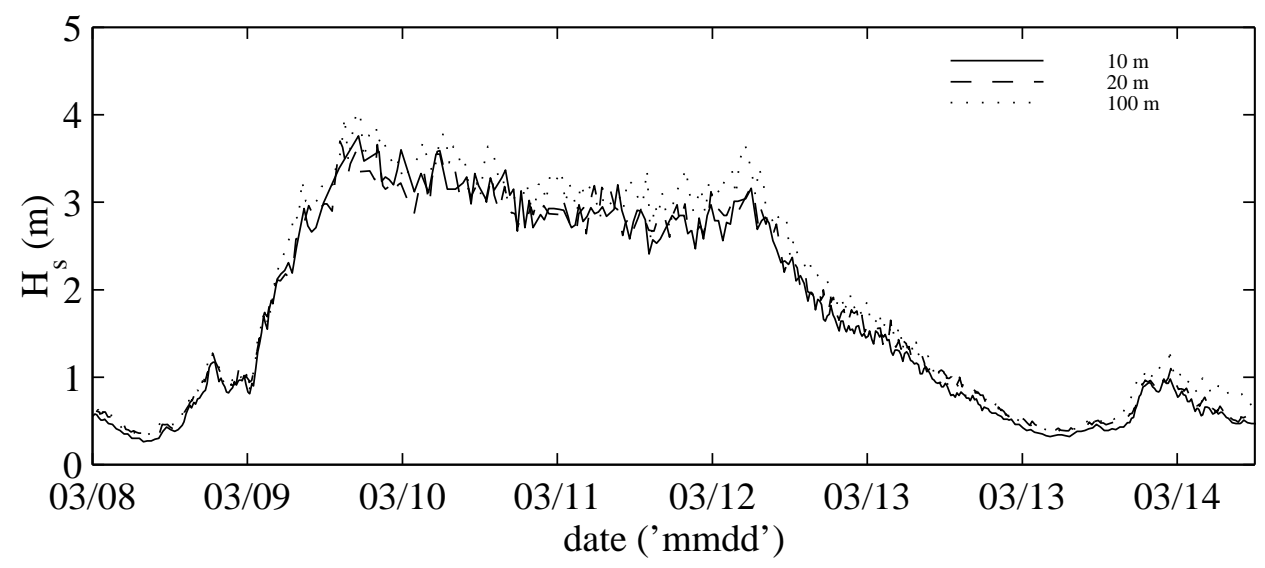

11. End of the storm $\left(\mathrm{H}_{\mathrm{S}}\right)$.

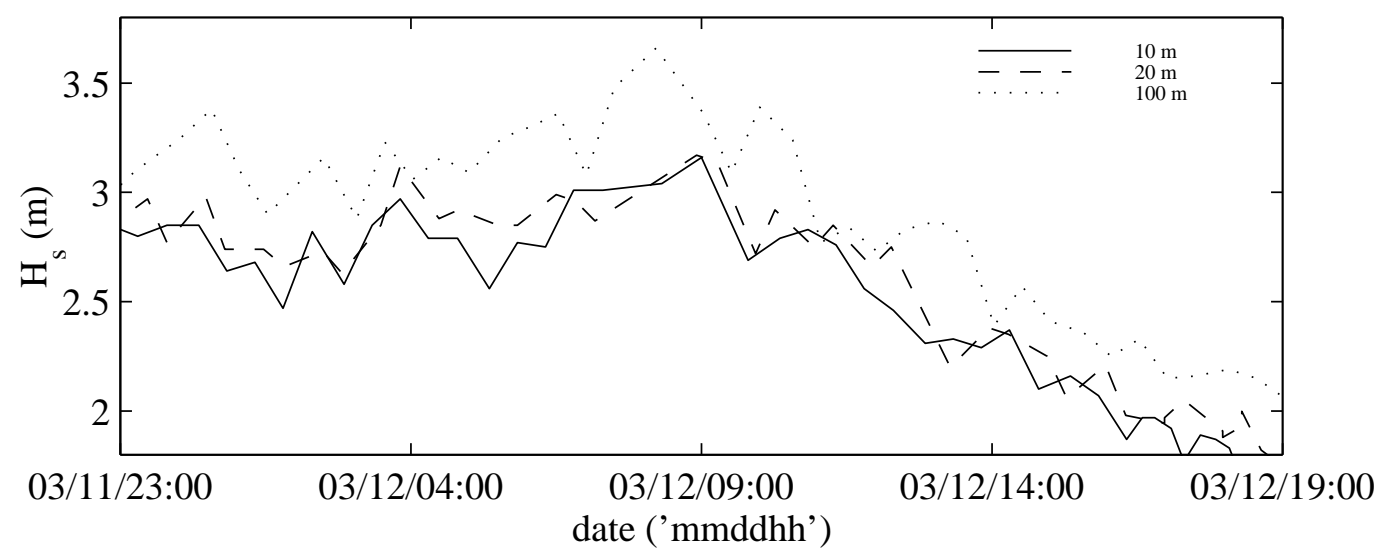

12. End of the storm $\left(T_{z}\right)$.

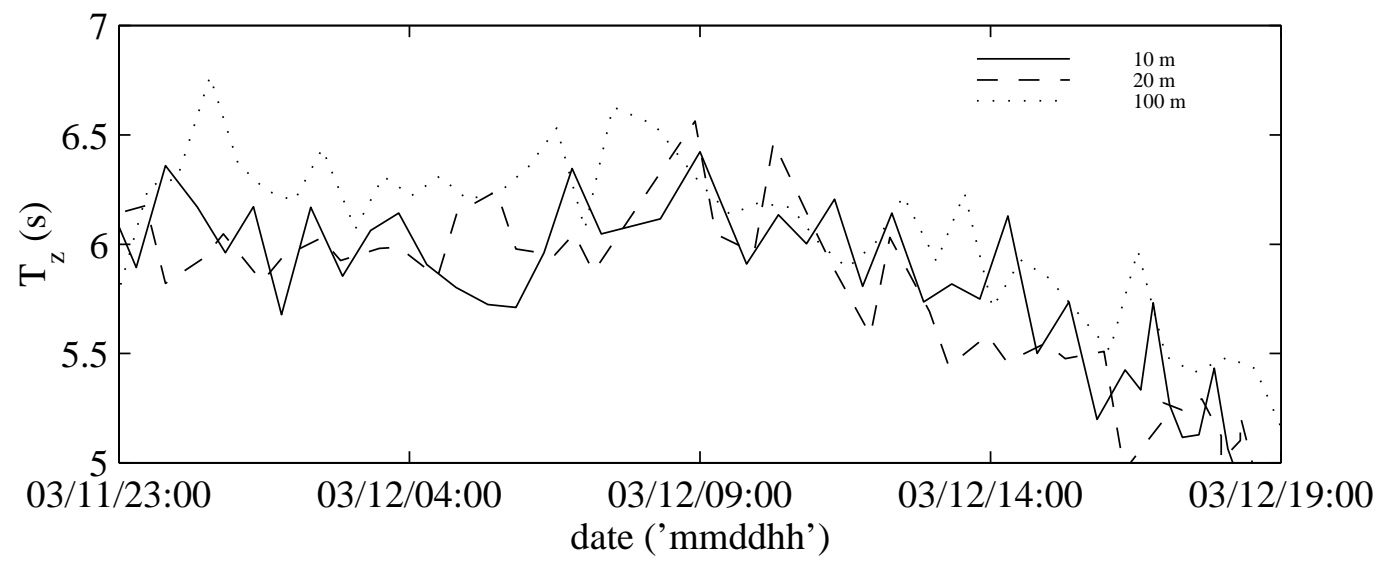


13. $H_{s}-T_{Z}$ diagram
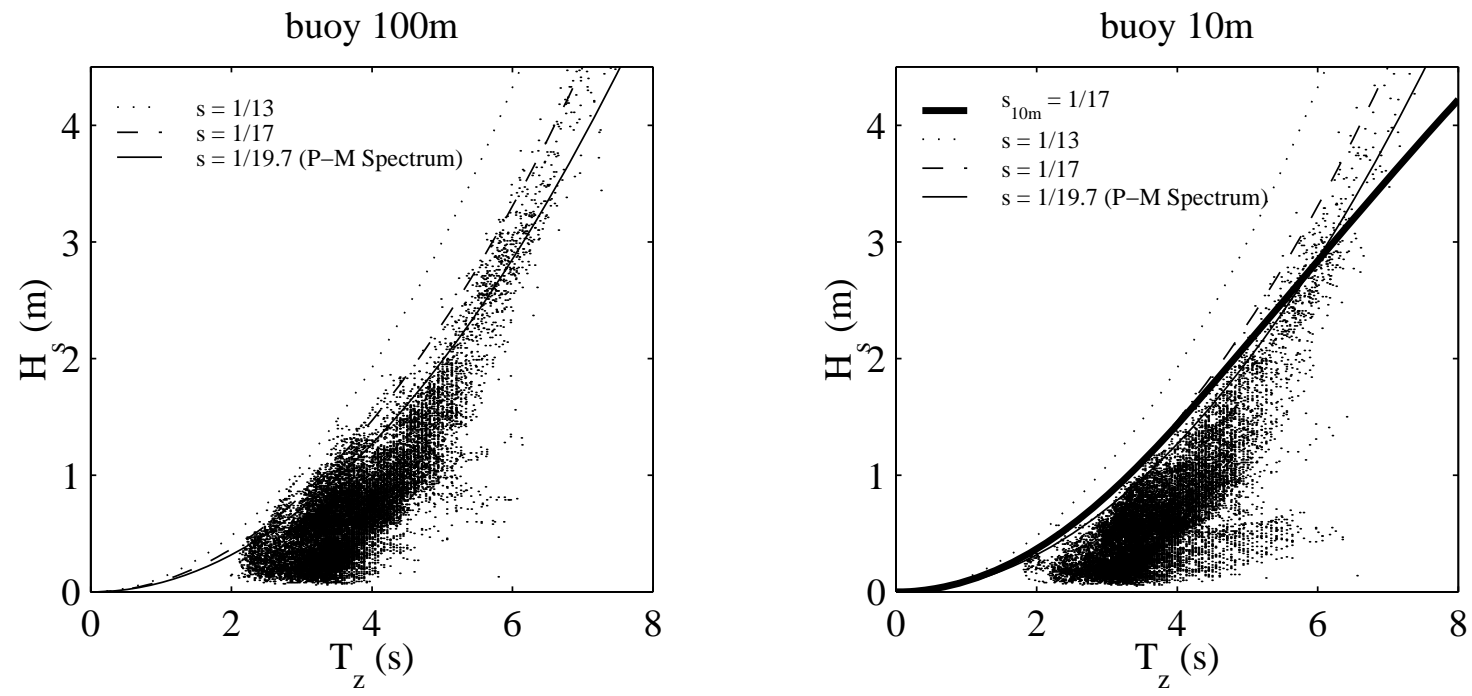